\title{
Estimation and Proposition Concerning Urban Environment by Means of the Use of the Five Senses' Icons by Elementary School Children
}

\author{
Kenji ICHIKAWA* and Shoichiro SENDAI** \\ * Graduate School, Hiroshima University, 1-4-1 Kagamiyama, Higashihiroshima, Hiroshima 739-8527, Japan \\ ** Hiroshima University, 1-4-1 Kagamiyama, Higashihiroshima, Hiroshima, 739-8527, Japan
}

\begin{abstract}
This paper aims to consider the proposition concerning urban environments regarding the change from the third to the fourth grade. The method can be categorized into two stages, the first being the conduction of the fieldwork and the workshop, organized as follows (1) "attempt to research", (2) "attempt to select signs", (3) "attempt to select icons", (4) "attempt to propose" and (5) "attempt to criticize", the second being the comparison of the tendency about the result data. According to the analysis, when the child passes from the third to the fourth grade, he/she turns out to estimate the urban environment more objectively, and comes to propose conservatively. However, we found that as for iconic expression related to the proposition phase, the five senses are maintained.
\end{abstract}

Keywords: Proposition, Five Senses' Icons, Child

\section{INTRODUCTION}

The authors have been practicing the methodology of the environmental map using the icons ${ }^{1}$, in order to consider the urban peace environment during the activities of "Hiroshima Eco-Peace Map" that has been conducting since 2002. Moreover, the authors drilled the program for improving the proposition capability with the themes of estimation, proposition and criticism from 2009. This was conducted with the children at the third grade of the Hiroshima University attached elementary school (39 persons). The same program proceeded on and was carried out with the children in question in the following year when they became the fourth grade (40 persons) in 2010.

Based on the activity in 2009, the authors already analyzed the relation between the estimation and the proposition for the living environment by the third grade children. As a result, it was found that the cognitive boundary between the living environment and the urban environment is not seen in the third grade children's propositions. On the other hand, we considered that their propositions include their egocentricity and their care of others within it [1-4].

1 The "icon" in this paper is extracted from the Green Map System Icons currently used in the urban production of environmental map by 400 or more cities.

(http://www.greenmap.org/greenhouse/gl_welcome/jp_welcome)

\section{OBJECTIVES}

This paper compares and analyzes the estimation and proposition of the urban environment by the children when they turn the fourth grade. Further, the paper examines the change of proposition capability for urban environments using icons by the children at the third/ fourth grades from the viewpoint of Kansei philosophy (as a qualitative study) [5].

The previous studies on workshop explored the future directions through the practices on art or those of urban planning [6,7].

Moreover, a few studies on the living environmental map by children are seen with the theme of history (like a "three-generation playground map"), and the theme of the five senses. In these studies, the connection with urban planning was attempted $[8,9]$.

Furthermore, some studies on proposition were conducted with the theme of children's participation for urban planning $[10,11]$ and the theme of improvement for the present circumstances [12].

In contrast, this study highlights the children's sensitivity for the urban environment through a series of process from the estimation to the proposition as the theme, by using five senses' icons. Also, it should be emphasized that this study targets at the same children for two years in the same area. 


\section{METHODS}

In principle, since the paper was done with the same children from the third grade passing to the fourth grade, this was included into the Integrated Study Curriculum in Japan.

We encouraged the children to make groups (from five persons to six persons) from A to $\mathrm{G}$ by themselves. Two university students, including both undergraduates and postgraduates of Hiroshima University, were allocated to each of the groups as supporters. In addition, some children's parents participated in the same group as children in the fieldwork.

Moreover, we made their own groups in the workshop, and set them to perform the same work children had done.

As the method to the proposition from the estimation, we set up (1)"attempt to research", (2) "attempt to select signs", (3) "attempt to select icons", (4) "attempt to propose", and (5) "attempt to criticize" (Table 1, 2). We operated (1) and (2) by the fieldwork simultaneously, and (3) to (5) by the workshop in the classroom of the elementary school.

The fieldwork on urban environment took place at the Nakajima area (the South Area), and at the Motomachi area (the North Area) (Figure 1). The signs which consist of spatial indexes (Good Place, Bad Place and Good/Bad

Table 1: The contents of activity in the third grade

\begin{tabular}{|c|c|c|}
\hline & & Fieldwork \\
\hline Date & Decemb & er 15th and 16th, 2009 \\
\hline Place & $\begin{array}{l}\text { Nakajim } \\
\text { in hirosh }\end{array}$ & $\begin{array}{l}\text { a area (the South Area) and Motomchi area (the North Area) } \\
\text { ima city }\end{array}$ \\
\hline Participant & Children & : 39 persons Parents : 18 persons \\
\hline & (1) attem & npt to research (2) attempt to select signs \\
\hline $\begin{array}{c}\text { The } \\
\text { contents of }\end{array}$ & 1st day & 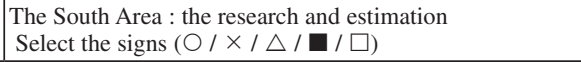 \\
\hline & 2nd day & $\begin{array}{l}\text { The North Area : the research and estimation } \\
\text { Select the signs }(\bigcirc / \times / \triangle / \square / \square)\end{array}$ \\
\hline & & Workshop \\
\hline Date & \multicolumn{2}{|c|}{ February 9th, 10th and 15th, 2010} \\
\hline Place & \multicolumn{2}{|c|}{ Hiroshima University attached elementary school } \\
\hline Participant & \multicolumn{2}{|c|}{ Children : 39 persons Parents : 14 persons } \\
\hline \multirow{10}{*}{$\begin{array}{c}\text { The } \\
\text { contents of } \\
\text { practice }\end{array}$} & \multicolumn{2}{|c|}{ (3) attempt to select icons } \\
\hline & \multirow[t]{2}{*}{ 1st day } & $\begin{array}{l}\text { The South Area and the North Area : the estimation } \\
\text { Select the kind of icons for the signs (see/ hear/ smell/ } \\
\text { taste/ touch) } \\
\text { Select the color of icons for the signs (Green / Red/Yellow) }\end{array}$ \\
\hline & & Presentation by parents and discussion \\
\hline & \multicolumn{2}{|c|}{ (4) attempt to propose } \\
\hline & \multirow{3}{*}{ 2nd day } & Presentation by children and discussion \\
\hline & & $\begin{array}{l}\text { The South Area and the North Area : the proposition } \\
\text { Writing the proposition (Green to Green/ Red to Green/ } \\
\text { Yellow to Green) }\end{array}$ \\
\hline & & Presentation by parents and discussion \\
\hline & \multicolumn{2}{|c|}{ (5) attempt to criticize } \\
\hline & \multirow[b]{2}{*}{ 3rd day } & Presentation by children and discussion \\
\hline & & $\begin{array}{l}\text { The South Area and the North Area : the criticism } \\
\text { Criticize the presentation of supporter's proposition and } \\
\text { discussion }\end{array}$ \\
\hline
\end{tabular}

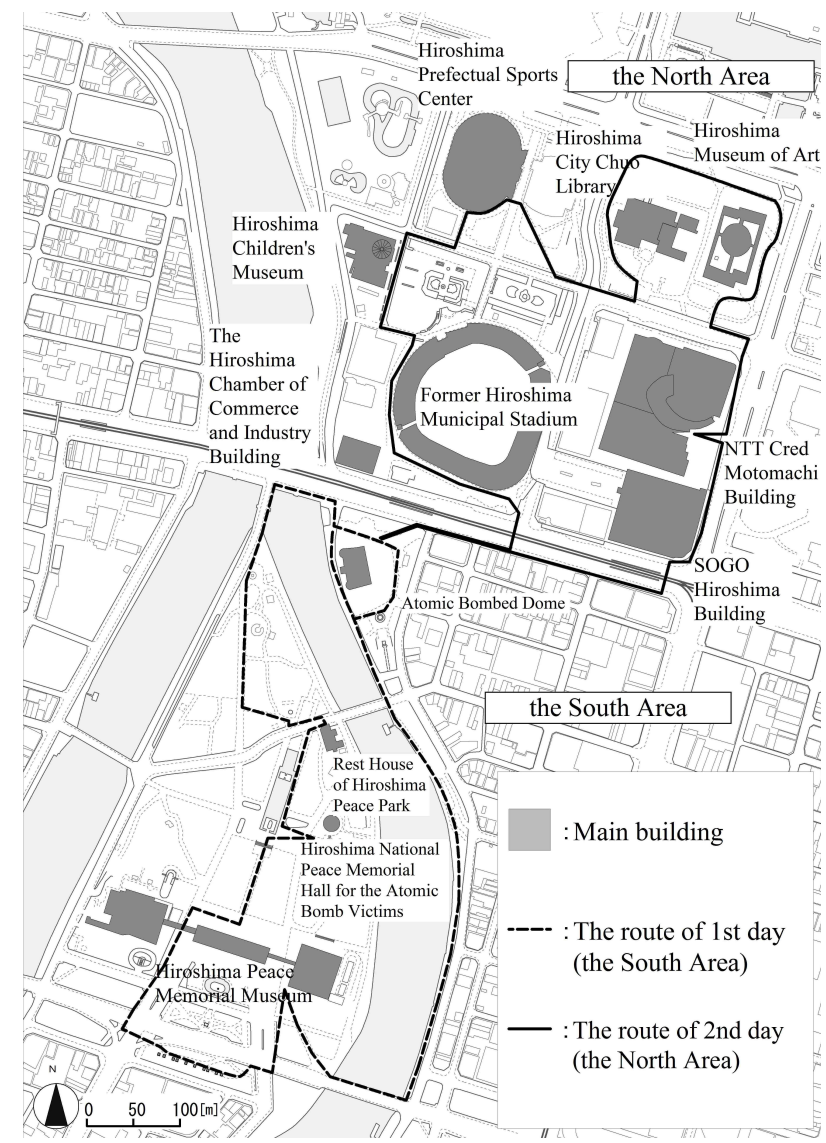

Figure 1: The range of survey in the fieldwork (both grade)

Table 2: The contents of activity in the fourth grade

\begin{tabular}{|c|c|c|}
\hline \multicolumn{3}{|r|}{ Fieldwork } \\
\hline Date & \multicolumn{2}{|c|}{ November 24th and 26th, 2010} \\
\hline Place & \multicolumn{2}{|c|}{$\begin{array}{l}\text { Nakajima area (the South Area) and Motomchi area (the North Area) } \\
\text { in hiroshima city }\end{array}$} \\
\hline Participant & \multicolumn{2}{|c|}{ Children : 39 persons Parents : 5 persons } \\
\hline \multirow{3}{*}{$\begin{array}{l}\text { The } \\
\text { contents of } \\
\text { practice }\end{array}$} & \multicolumn{2}{|c|}{ (1) attempt to research (2) attempt to select signs } \\
\hline & 1 st day & $\begin{array}{l}\text { The South Area : the research and estimation } \\
\text { Select the signs }(\bigcirc / \times / \triangle / \square)\end{array}$ \\
\hline & 2nd day & $\begin{array}{l}\text { The North Area : the research and estimation } \\
\text { Select the signs }(\bigcirc / \times / \triangle / \square / \square)\end{array}$ \\
\hline \multicolumn{3}{|r|}{ Workshop } \\
\hline Date & \multicolumn{2}{|c|}{ February 15th, 16th, 18th and 23rd, 2011} \\
\hline Place & \multicolumn{2}{|c|}{ Hiroshima University attached elementary school } \\
\hline Participant & \multicolumn{2}{|c|}{ Children : 40 persons } \\
\hline \multirow{11}{*}{$\begin{array}{l}\text { The } \\
\text { contents of } \\
\text { practice }\end{array}$} & \multicolumn{2}{|c|}{ (3) attempt to select icons } \\
\hline & \multirow[t]{2}{*}{ 1st day } & $\begin{array}{l}\text { The South Area and the North Area : the estimation } \\
\text { Select the kind of icons for the signs (see/ hear/ smell/ } \\
\text { taste/ touch) } \\
\text { Select the color of icons for the signs (Green / Red/Yellow) }\end{array}$ \\
\hline & & Presentation and discussion \\
\hline & \multicolumn{2}{|c|}{ (4) attempt to propose } \\
\hline & \multirow[t]{2}{*}{ 2nd day } & $\begin{array}{l}\text { The South Area and the North Area : the proposition } \\
\text { Writing the proposition (Green to Green/ Red to Green/ } \\
\text { Yellow to Green) }\end{array}$ \\
\hline & & Presentation by parents and discussion \\
\hline & \multicolumn{2}{|c|}{ (4) attempt to propose } \\
\hline & \multirow[t]{2}{*}{ 3rd day } & $\begin{array}{l}\text { The South Area and the North Area : the proposition } \\
\text { Drawing the original icon }\end{array}$ \\
\hline & & Presentation by guardians and discussion \\
\hline & \multicolumn{2}{|c|}{ (5) attempt to criticize } \\
\hline & 4th day & $\begin{array}{l}\text { The South area and the North area : the criticism } \\
\text { Criticize the presentation of supporter's proposition and } \\
\text { discussion }\end{array}$ \\
\hline
\end{tabular}


Place), and time indexes (Lost Place and Future Place). The estimation place and the route could cover main buildings and monuments, returning to the starting point within 3 hours, and it was considered safe for the children. Moreover, they are the same conditions at the third/fourth grades.

In the workshop, we instructed children to select from the five senses' icons (see, hear, smell, taste and touch) (Figure 3) correlating to the signs expressed in the estimation of the fieldwork. In addition, we made children to express by means of colors (Green means affirmation, Red means negation, and Yellow means neutrality or affirmation/negation) (Figure 2). That is, in order to lead the children's estimation and proposition based on body feeling, we used the "five senses" what simplified the concept of the "Hiroshima Eco-Peace Map".

As mentioned above, we total the data which was obtained in the fieldwork and workshop for the urban environment. Also, we compare and analyze the tendency of estimation and proposition at the third/fourth grades in each stage.

\section{ANALYSIS OF "ATTEMPT TO SELECT SIGNS"}

\subsection{Estimation with Signs (Spatial Index) (Figure 4)}

In the North Area and the South Area, the rate of "Good Place" is more than $60 \%$ at the third/fourth grades. However, when the children passed from the third to the fourth grade, in both Areas, the rate of "Bad Place" is increasing about $10 \%$.

\subsection{Estimation with Signs (Time Index) (Figure 5)}

In the North Area and the South Area, when the children passed from the third to the fourth grade, the rate of "Future Place" increases about $20 \%$.

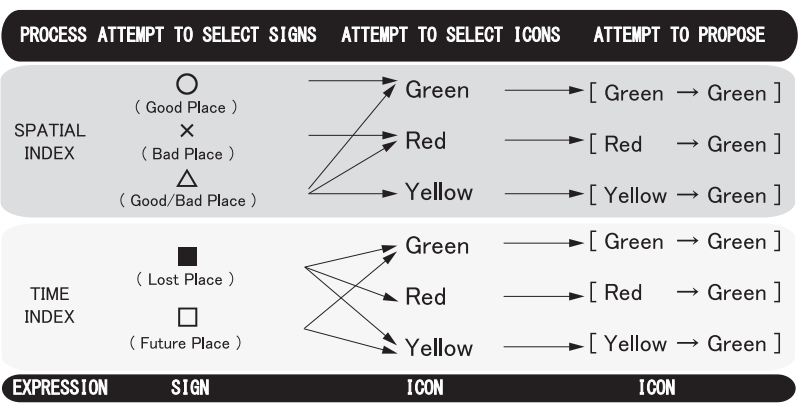

Figure 2: The flow from the fieldwork to the workshop

\begin{tabular}{|c|c|c|c|c|c|}
\hline meaning & see & hear & smell & taste & touch \\
\hline icon & & 2 & 2 & & \\
\hline
\end{tabular}

Figure 3: The five sense's icons

\subsection{The Object of Estimation with Signs (Figures 6, 7)}

In the North Area, when the children passed from the third to the fourth grade, the rate of "architecture (building)" and "architecture (monument)" decreases about

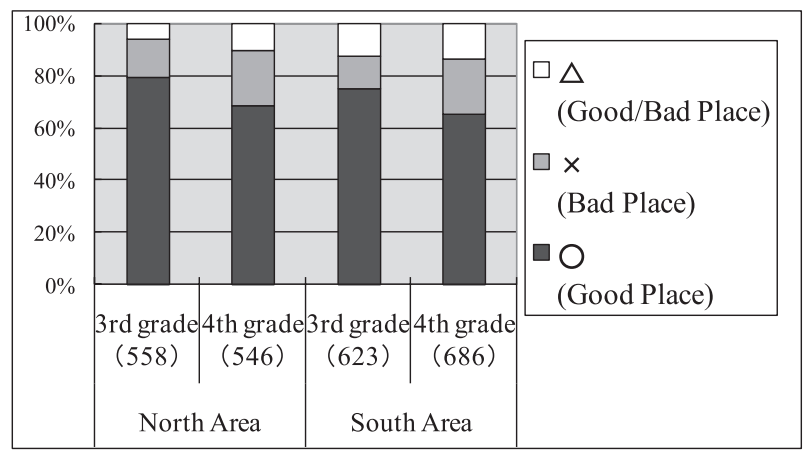

Figure 4: The rate of estimation by signs (Spatial Index)

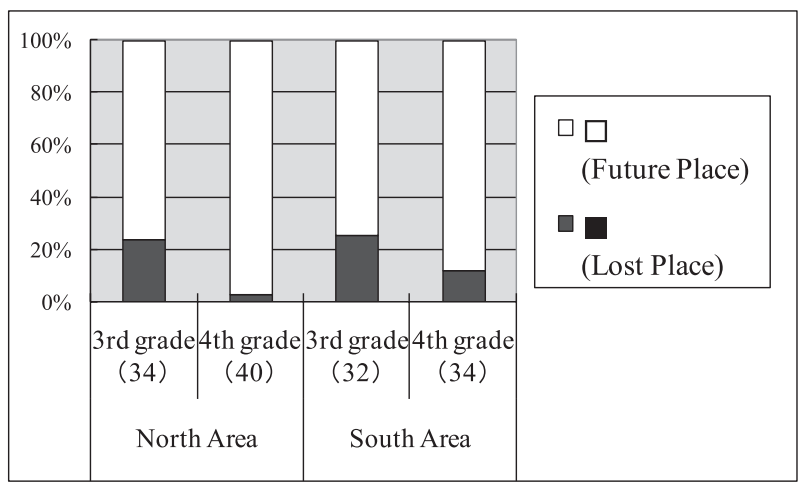

Figure 5: The rate of estimation by signs (Time Index)

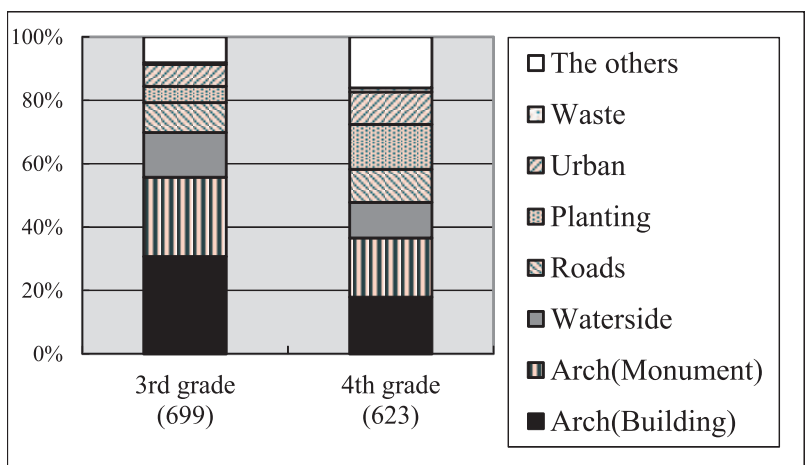

Figure 6: The rate of object for estimation (the North Area)

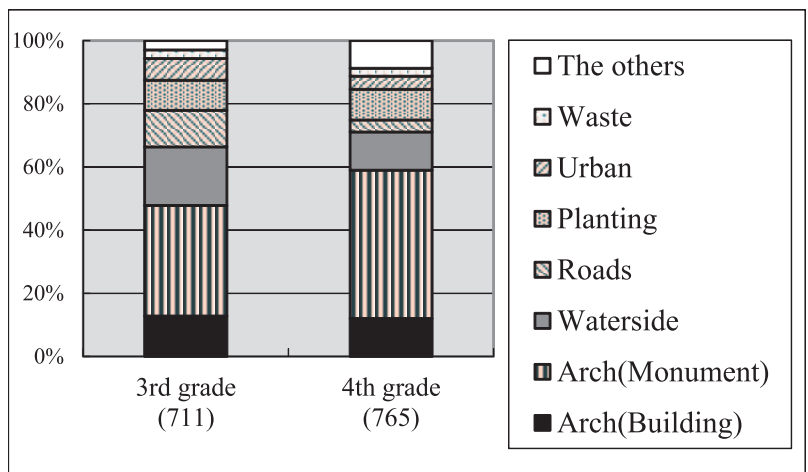

Figure 7: The rate of object for estimation (the South Area) 
10\%. In the South Area, when the children passed from the third to the fourth grade, the rate of "architecture (monument)" increases about $10 \%$.

\section{ANALYSIS OF "ATTEMPT TO SELECT ICONS"}

\subsection{Estimation by the Color of Icons (Spatial Index) (Figure 8)}

At both grades, the rate of Green is more than $60 \%$. This is the highest estimation regarding the urban environment in the affirmative. However, at the fourth grade, the rate of Red is increasing about $10 \%$, and it is a negative estimation. This is the same tendency with "attempt to select signs" we consider a definite tendency

\subsection{Estimation by the Color of Icons (Time Index) (Figure 9)}

When the children passed from the third to the fourth grade, the rate of Yellow increased more than $10 \%$. This is a critical estimation. We consider a definite tendency to relevant estimation for spatial index.

\subsection{Estimation by the Kind of Icons (Spatial Index) (Figure 10)}

At both grades, the rates of "see" and "touch" soar, and occupy more than $70 \%$ in all. Moreover, it is not noticed

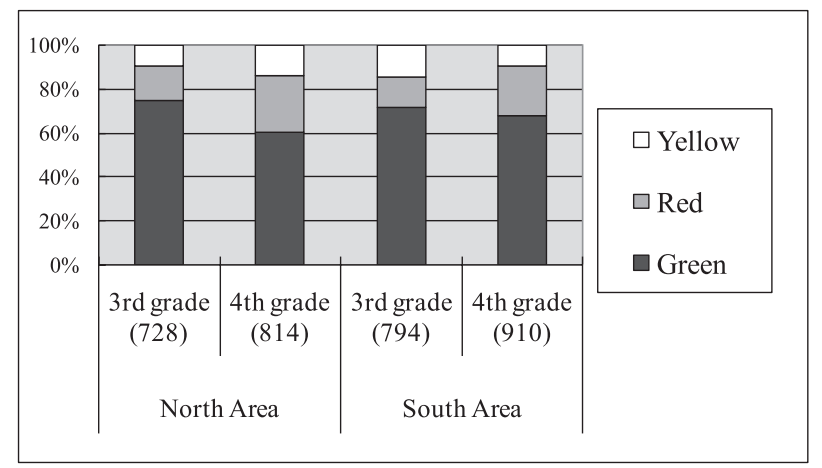

Figure 8: The rate of estimation by the color of icons (Spatial Index)

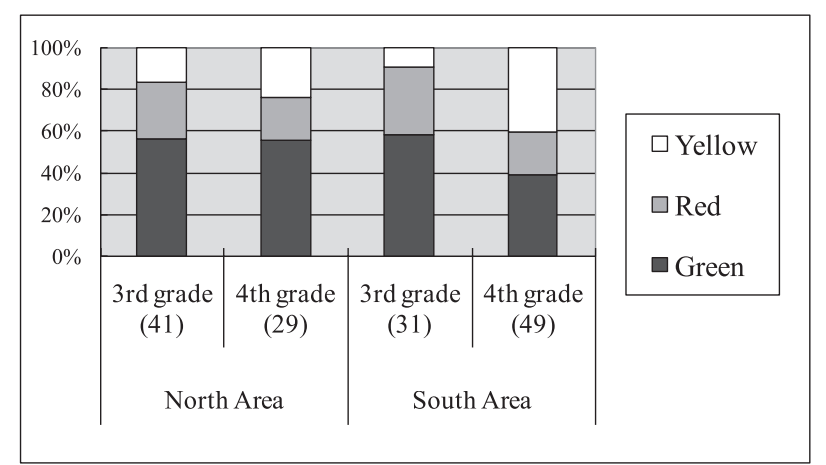

Figure 9: The rate of estimation by the color of icons (Time Index) an extreme low percentage of any kind within the five icons.

\subsection{Estimation by the Kind of Icons (Time Index) (Figure 11)}

At the fourth grade, the rate of "see" gets low, and occupies less than $40 \%$ in total. That is, when the children passed from the third to the fourth grade, the tendency to estimate using other senses except "see" icon becomes high. We consider a definite tendency to be relevant as estimation for spatial index.

\section{ANALYSIS OF "ATTEMPT TO PROPOSE"}

\subsection{The Object for a Proposition (Figures 12, 13)}

In the North Area, when the children passed from the third to the fourth grade, the rate of "architecture (building)" decreased about 20\%, and the rate of "architecture (monument)" decreased about $10 \%$. The children's interests drift about towards the "waterside", "planting" and "road" rather than "architecture". This is the same tendency as the stage of "attempt to select signs", and we consider a definite tendency.

In the South Area, when the children passed from the third to the fourth grade, the rate of "architecture (monument)" increased about 10\%. The children's interests

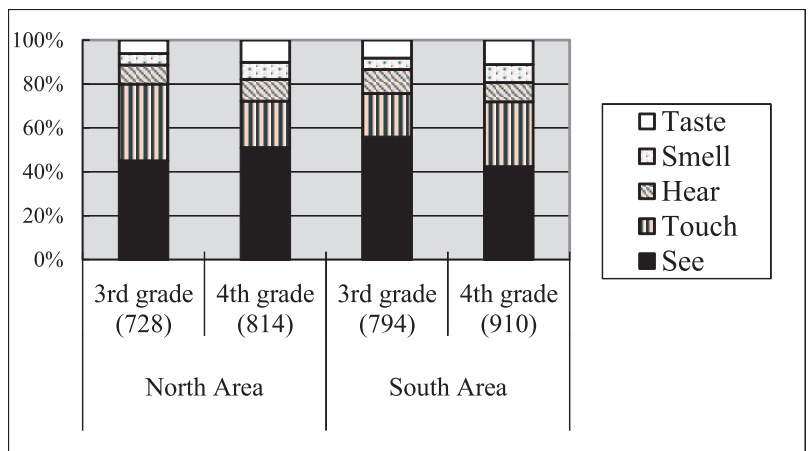

Figure 10: The rate of estimation by the color of icons (Spatial Index)

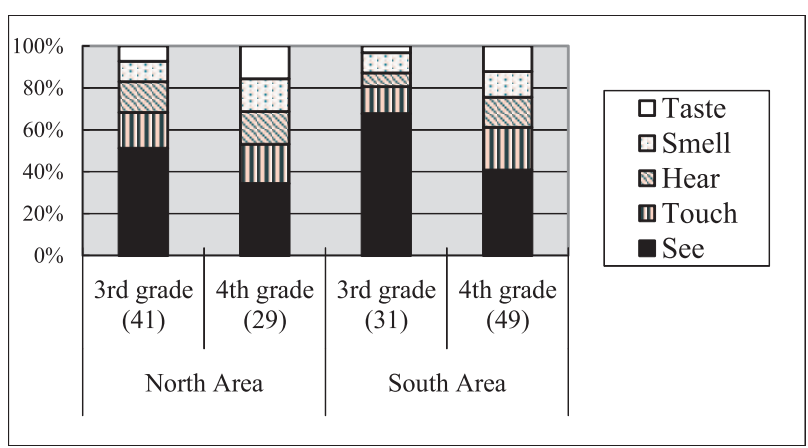

Figure 11: The rate of estimation by the color of icons (Time Index) 


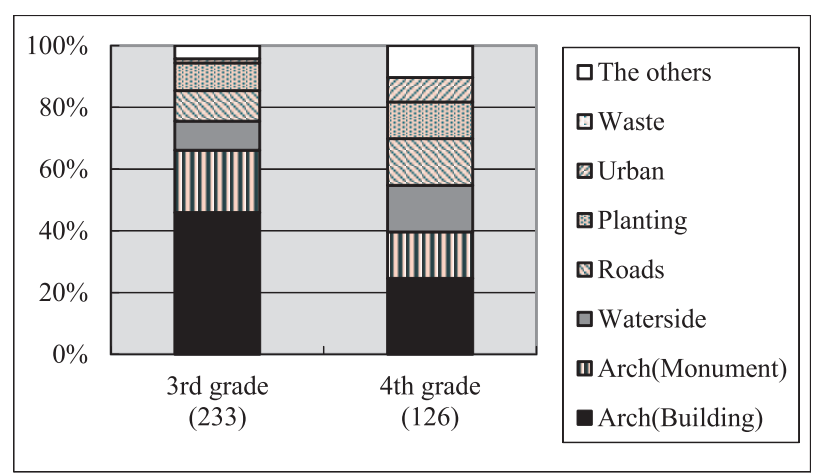

Figure 12: The rate of object for proposition (the North Area)

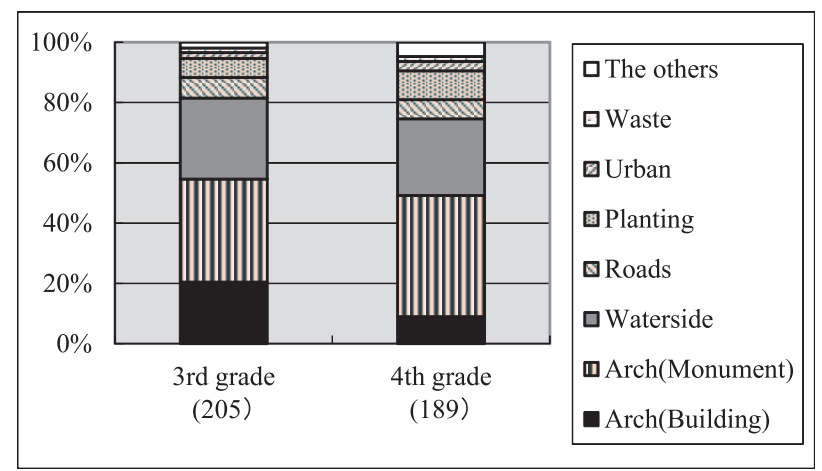

Figure 13: The rate of object for proposition (the South Area)

shift to the "architecture (monument)". This is the same tendency as the stage of "attempt to select signs", which we consider another definite tendency.

\subsection{The Method of Proposition by Writings (Figure 14)}

The proposition which was described by writings was classified into the "soft" proposition or the "hard" proposition according to the degree of humanity.

In the North Area or the South Area, at both grades, the rate of "hard" proposition is higher than the rate of "soft" proposition. We consider this to be a definite tendency.

\subsection{The Purpose of Proposition by Writings (Figure 15)}

The proposition which was described by writings was classified into development, reproduction and preservation according to the degree of development.

In the North Area or the South Area, at both grades, the rate of "development" is high, and occupies more than $60 \%$.

However, the rate of "reservation" at the fourth grade is higher than the rate for "reservation" assigned by the third grade, and occupies $30 \%$. We can guess that the purpose of proposition is a conservative tendency.

\subsection{The Content of Proposition by Writings (Figure 16)}

The proposition which was described by writings was classified into "ego" and "care" according to the degree of egocentricity.

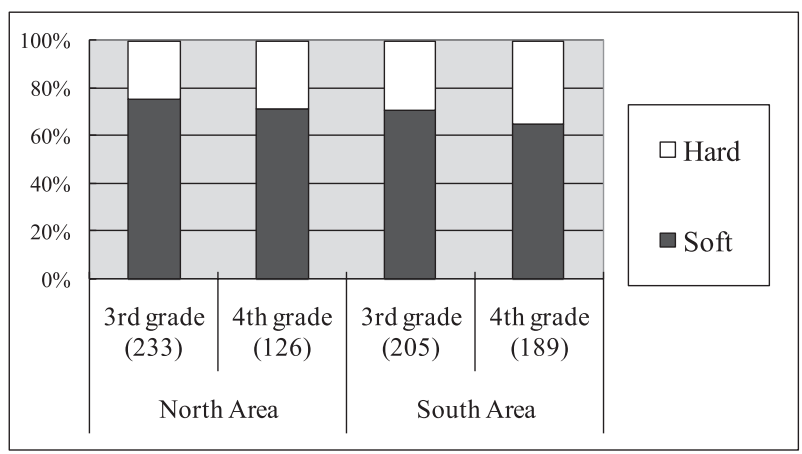

Figure 14: The rate of the method of proposition (Writings)

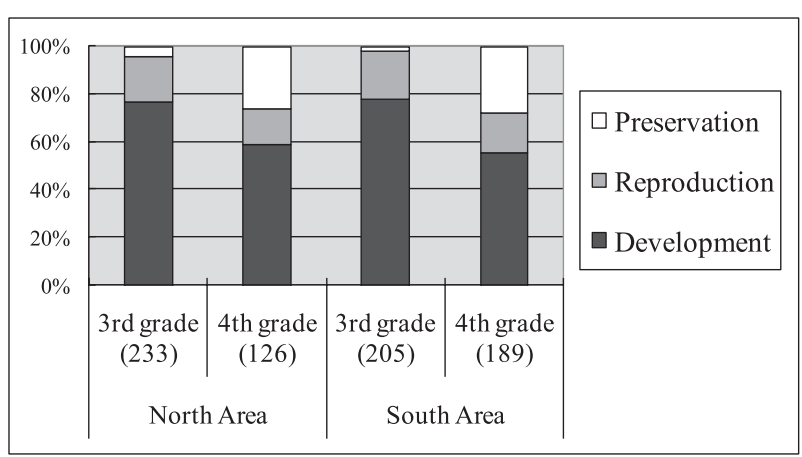

Figure 15: The rate of the purpose of proposition (Writings)

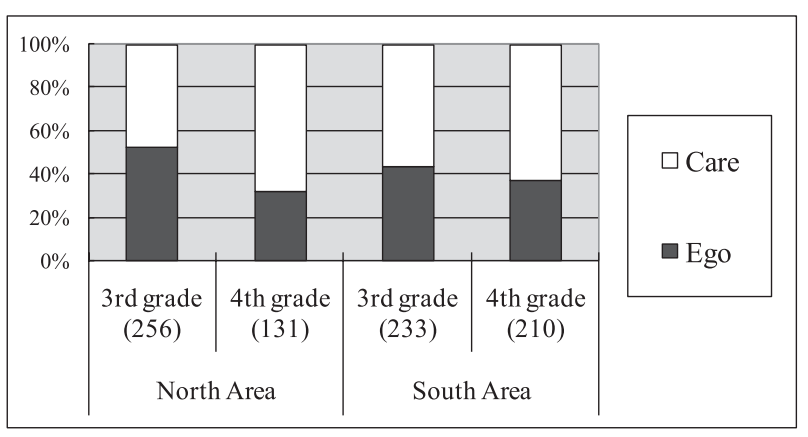

Figure 16: The rate of contents of proposition (Writings)

The rate of "care" occupies more than 50\% in both grades. In particular, when the children passed from the third to the fourth grade, the rate of "care" increased 20\% in the North Area. These differ from the proposition which includes "ego" and "care" ambivalently in the third grade. We thought that this is a definite tendency relevant to increase the case that "ego" is not including "care" at the fourth grade.

\subsection{The Purpose of Proposition by the Color of Icons (Figure 17)}

About the icon drawn corresponding to writings, at both grades, the rate of "from Green to Green" is the highest and occupies more than 50\%.

However, the rate of "from Red to Green" at the fourth grade is higher than the rate of "from Red to Green " at 
the third grade, and about $10 \%$ increased. When the children passed from the third to the fourth grade, their consciousness of improvement for environment are growing. That is to say, the tendency that the children catch the present environment negatively is the same tendency of the estimation by the color of icons, and we consider that a definite tendency.

\subsection{The Method of Proposition by the Kind of Icons (Figure 18)}

About the icon drawn corresponding to writings, the rate of "touch" increased about $10 \%$ by the fourth grade in the North Area. On the other hand, in the South Area, the rate of "taste" increased slightly by the fourth grade (about 5\%). However, even if it considers these differences to be faults, the fractional rate of the five senses' icons of both grades is mostly similar.

\section{CONCLUSION}

\subsection{Result}

According to each analysis, the characteristic at the third/fourth grade is summarized in the following Table 3. Gray color parts are expressed the big transition from the third grade. Based on this table, when the children passed from the third to the fourth grade, the transition about the estimation and proposition for the urban environment is as follows:

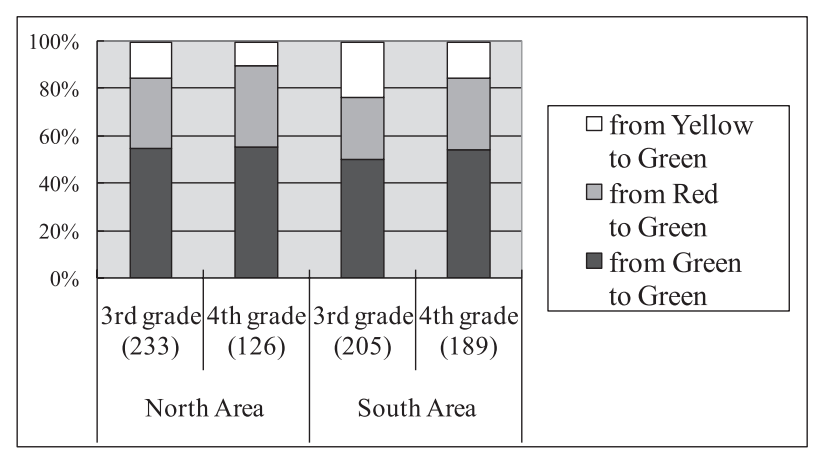

Figure 17: The rate of purpose of proposition (Icons)

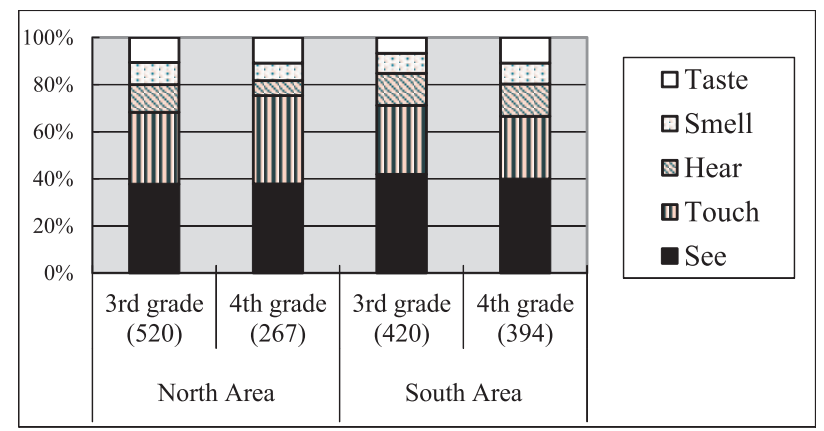

Figure 18: The rate of method of proposition (Icons)

\section{(1) Estimation}

When the children passed from the third to the fourth grade, the sign of "Bad place" and Red become remarkable in both Areas. Children became to be able to perform the objective estimation. On the other hand, the icons without "see" increased at the fourth grade in both Areas. That is to say, children have not necessarily made a visual judgment simply.

(2) Proposition

Such an objectification of estimation is accelerating the conservatism of proposition by writings. However, there is no change on iconic expressions in using the five senses.

\subsection{Discussion}

The above result is more evident an extract of students' oral presentations about proposition that uses icons of Peace Bell at the same estimated place when they were the third or fourth grade.

"From Green to Green, at the Peace Bell, now the place is nothing around, so I propose decorating the place with "Senba Tsuru." If the proposition ever realizes, I think the place is happy. The estimation by the kind of icons were "hear" and "touch" while the proposition by the kind of icons were "see", "hear" and "touch." (the third grade, group is $\mathrm{C}$ )

"From Green to Green, at the Peace Bell, I fell good listening to ring bell. I propose the person who rings the bell to write his/her country's name in some paper. If the proposition realizes, in the world, he/she fell peace. So I think that the nuclear is nothing. I select the sign "the good place", the estimation by the kind of icons was "see", "hear" and "touch" while the proposition by the kind of icons were "see", "hear" and "touch." (the fourth grade, group is $\mathrm{G}$ )

We can see that the fourth grade students use their five senses as same as the third grade students or more than that from expressions of icons, even if there are conservative of propositions.

In writings, at the moment when the children pass from the third to the fourth grade, they are in general growing up and maturing the ability of space perception [13].

Moreover, the objectification of estimation and the conservative of proposition at the fourth grade students would be the reflection what they can become to change propositions into objectification.

It is evident as to propositions in the dimension of writings. However, in the dimension of icons, we can see that the base of the propositions is the five senses which are unchanged from the third grade [14]. 


\section{REFERENCES}

1. Shoichiro Sendai (2010). Estimation and Proposal to the Living Environment by Means of the Use of the Five Senses' Icons by the Third Graders of the Elementary School. Kansei Philosophy 10, Japan Society of Kansei Engineering, pp.146-168.

2. Shoichiro Sendai, Isao Mitsuhata (2010). Estimation and Proposal to the Living Environment by Means of the Use of the Five Senses' Icons by the Third Graders of the Elementary School. The collection of the 11th Kansei Engineering convention drafts, 3C1-3_ J12-100518-3.pdf.

3. Shoichiro Sendai, Isao Mitsuhata (2011). Estimation and Proposal Concerning the Public Space by Means of the Use of the Five Senses' Icons by the Third Graders of the Elementary School. Kansei Engineering International Journal Vol.10, No.2, pp.73-80.

4. Tadashi Suzuki (1996). The Child's Point of View: Studies on the Development of Spatial Cognition. University of Tokyo Press, Tokyo.

5. Toshio Kuwako (2001). Philosophy of Sensitivity. NHK publishing, Japan.

6. Yoichi Takahashi, Takahiro Sugiyama (2001). The Practice of Research in Workshop. University of Musashino Art press, Japan.

7. Yasuhiro Endo (2001). "Machi sodate wo Hgukumu". University of Tokyo Press, Japan.

8. Isami Kinoshita (2007). Workshop. Gakugeisha press, Japan.

9. Kiyoshi Teramoto (1996). The Interesting Map Training using the Five Senses. Meiji Library, Japan

10. Kiyoshi Teramoto (1999). The Planning by the Viewpoint of Children. KTC Chuo press, Japan.

11. Roger A. Hart, IPA Japan (E) (2000). Children's Participation. Hobunsha, Japan.

12. David D (2002). Creating Better Cities with Children and Youth: A Manual for Participation. Unesco Publishing, Paris.

13. Yoshiki Wakabayashi (1999). Spatial Analysis of Cognitive Map. Chijinshobo, Japan.

14. Shoichiro Sendai, Isao Mitsuhata (2011). Estimation and Proposal Concerning Life Environment by Means of the Use of the Five Senses' Icons by Elementary School Comparison Between Third And Fourth Graders. The collection of the 13th Kansei Engineering convention drafts, TJSKE-D-11-00037.pdf.

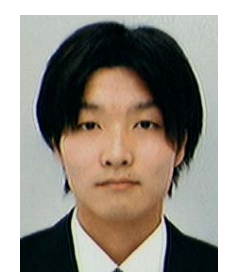

\section{Kenji ICHIKAWA}

Kenji Ichikawa is a designer of Kumagai Gumi. He graduated from Hiroshima University, department of architecture in March, 2012.

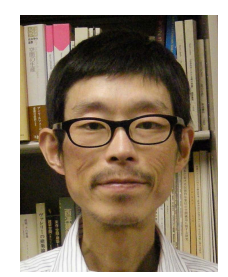

\section{Shoichiro SENDAI}

1968, Born in Kyoto. 1998, Doctor Course Graduate School, Division of Engineering, Kyoto University. Associate Professor, Doctor Eng., Graduate School of Engineering (Division of Social Environment and Space) Hiroshima University. Major Publications: Kansei Field (Toshindo, 2012), Fudo in City (Minerva, 2009), Technique and Body (Minerva, 2006), The Creation and "the Architectural landscape" : the religious architecture of Le Corbusier (Chuokoron-bijutsusyuppan, 2004) (Award of Japanese Society of Kansei Engineering, 2004), etc.. Main works : the modern architectural landscape of Le Corbusier, the history of peace in Hiroshima and the children's environment. 